\title{
About the New Editor-in-Chief
}

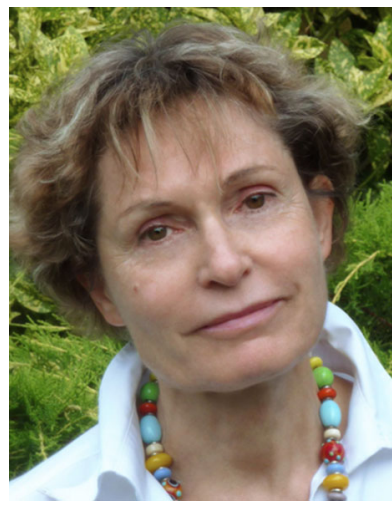

Professor Armelle Vardelle, FASM, University of Limoges, France, has been named Editor-in-Chief of the Journal of Thermal Spray Technology (JTST), announced Dr. Robert C. Tucker, Jr., FASM, TS HoF, Chair of the JTST Editorial Committee. Professor Vardelle has been a member of the journal editorial staff for a number of years. She was an associate editor of the journal from 2006 through 2012 and became Lead Editor in 2013. She succeeds Dr. Christian Moreau, FASM, TS HoF, Canada Research Chair, Thermal Spray and Surface Engineering, Concordia University, who served the journal as editor-in-chief for the past 12 years.

Professor Vardelle (D.Sc. 1987; Ph.D. 1979, M.Sc. 1975, B.Sc. 1973) is Co-Chair of the Department of Materials (Surface Treatments and Environment) at the Engineering School of the University of Limoges (Ecole Nationale Supérieure d'Ingénieurs de Limoges, ENSIL), France. She holds the title of Distinguished Professor and is involved in research in the laboratory of Sciences of Ceramics and Surface Treatment Processes, UMR-CNRS in the European Ceramic Center.

Her current research interests are thermal spray and thermal plasma processes, modeling of plasma processes and torch operation, transport and chemical rate phenomena at hightemperature, thermal-sprayed coatings, and green manufacturing. Her teaching interests include thermal spraying, surface engineering, thermal sciences, transport phenomena in surface engineering processes, materials properties, industrial ecology, and life cycle analysis.

Professor Vardelle has authored or coauthored more than 111 peer-reviewed scientific journal publications, 141 publications in International and National Conference Proceedings, and seven book chapters. She has presented 42 invited lectures at international conferences and 11 invited seminars at foreign universities.

In addition to her contributions to JTST, Professor Vardelle has been a member of the Editorial Board of Plasma Chemistry and Plasma Processing since 2009. She became a Fellow of the International Plasma Chemistry Society in 2015, and a Fellow of ASM International in 2012. 